Research Article

\title{
Long-Term Impact of Coronary Artery Disease in Lung Transplantation
}

\author{
William S Ragalie ${ }^{1}$, Nilto C de Oliveira ${ }^{2}$, Richard Cornwell ${ }^{3}$, Keith \\ Meyer $^{3}$ and James D Maloney ${ }^{2,4 *}$
}

${ }^{1}$ Department of Surgery, Medical College of Wisconsin, Wisconsin, USA

${ }^{2}$ Division of Cardiothoracic Surgery, Department of Surgery, University of Wisconsin Hospitals and

Clinics, Madison, Wisconsin, USA

${ }^{3}$ Division of Pulmonary Medicine, Department of Medicine, University of Wisconsin Hospitals and Clinics,

Madison, Wisconsin, USA

${ }^{4}$ Middleton Memorial VA Hospital, Madison Wisconsin, USA

\section{Abstract}

Background: Adoption of the Lung Allocation Score (LAS) has led to increased listing of older patients and those with idiopathic pulmonary fibrosis (IPF) for lung transplantation (LTX). Older patients and those with IPF have higher prevalence of coronary artery disease (CAD), a relative contraindication for LTX. The impact of the LAS on CAD prevalence and cardiovascular morbidity in LTX recipients is unknown.

Methods: Retrospective review of single institution database from January 2000 to December 2010. Patients with and without CAD were compared by age, gender, LAS, single vs double LTX, and transplant indication. Survival was calculated by Kaplan-Meier method, and statistical significance determined by log-rank method. Survival analysis was performed on all patients and by 3:1 propensity matching. Differences in CAD, gender, and indication were determined by Chisquared test. Differences in LAS and age were calculated with a two-tailed $t$ - test.

Results: In the pre-LAS era, $6.2 \%(9 / 145)$ recipients had CAD vs. $9.2 \%(17 / 184)$ in the postLAS era $(p=0.411)$. Among all patients, recipients with CAD had a worse long term survival as estimated by Kaplan-Meier method $(p=0.001)$, although there was no statistically significant difference after propensity matching $((p=0.14)$. Although more recipients in the post-LAS era had a diagnosis of IPF [15/145 vs. 71/184 patients, $(p<0.001)]$, there was no difference in the prevalence of CAD in the IPF cohort compared to others. There were no differences in cardiovascular deaths among recipients with CAD, with IPF, or in the post-LAS era. Patients with a pre-transplant diagnosis of $C A D$ had an descreased risk of new onset postoperative atrial fibrillation (AF) ( $p=0.007$; HR:0.133; Cl:0.030-0.583).

Conclusion: Adoption of the LAS was not associated with a significant change in proportion of recipients with CAD who underwent LTX at our institution, despite an increase in recipients with IPF. Recipients with CAD had a higher risk of developing new postoperative AF and worse survival than patients without CAD. Differences in survival, however, could not be attributed directly to CAD based on propensity matched analysis.

\section{Background}

Lung transplantation (LTX) is a high-risk, resource intensive clinical undertaking. Survival after lung transplantation is lowest among all solid organ transplants, but there is a considerable survival benefit of transplanted patients compared to listed patients who do not receive a transplant [1]. Additionally, donor lungs that are acceptable for transplantation are a scarce resource, such that harvest rates range between $15 \%-20 \%$ from potential donors $[2,3]$.

\section{More Information}

*Address for Correspondence: James D Maloney, 600 Highland Ave, CSC H4/316, Madison, WI 53792-3236, Email: maloney@surgery.wisc.edu

Submitted: 13 November 2019

Approved: 25 November 2019

Published: 26 November 2019

How to cite this article: Ragalie WS, de Oliveira NC, Cornwell R, Meyer K, Maloney JD. LongTerm Impact of Coronary Artery Disease in Lung Transplantation. J Cardiol Cardiovasc Med. 2019; 4: 227-232.

DOI: dx.doi.org/10.29328/journal.jccm.1001073

Copyright: () 2019 Ragalie WS, et al. This is an open access article distributed under the Creative Commons Attribution License, which permits unrestricted use, distribution, and reproduction in any medium, provided the original work is properly cited.

Keywords: Adult; Lung transplantation; Atherosclerosis; Coronary artery disease; Lung allocation; Follow-up studies; Survival rate; Coronary disease in transplant

(7) Check for updates
Because of these factors, the recipient selection process aims to maximize transplant benefit for each recipient. Coronary artery disease (CAD) is a relative contraindication to LTX but this alone does not preclude listing of carefully selected patients at experienced centers. Several authors have reported a high prevalence of asymptomatic CAD in patients being screened for LTX [4,5], although there is debate about the optimal catheterization practice in evaluating patients with end-stage lung disease for listing [6]. Several groups have published favorable results of LT in patients with CAD, including 
concomitant coronary revascularization, demonstrating comparable short and long-term outcomes compared to LTX patients without CAD [7-9]. Interestingly, patients with idiopathic pulmonary fibrosis (IPF) are at increased risk of CAD compared to the general population, and the incidence and prevalence of CAD is higher in IPF compared to other forms of lung disease such as chronic obstructive pulmonary disease (COPD) [10-12]. IL-17 mediated autoimmunity to collagen type $\mathrm{V}$ appears to be a common pathway to both IPF and CAD [13-16], however to our knowledge the biological association between these two disease states has not yet been clearly elucidated. The relationship between IPF and CAD is especially critical in selecting patients for listing for LTX since the adoption of the Lung Allocation Score (LAS) in 2005 has led to an increase in the percentage of patients with IPF who undergo LTX, to the point where this diagnosis now represents the largest diagnostic cohort on the waiting list $[17,18]$. Furthermore, IPF patients are more likely to be among the highest risk cohorts as determined by LAS [19], and median survival of IPF patients is the lowest of all diagnostic groups who undergo LT [20]. These factors may have an important implication on outcomes; however, the relationship between IPF, CAD and the LAS has not previously been described in detail.

\section{Methods}

We identified all patients who had consecutively undergone lung transplantation at the University of Wisconsin from January 1, 2000 to December 31, 2010. Both single and bilateral lung transplants were included. Retrospective review of the prospectively gathered SRTR data was granted by the institution's independent review board. We identified patients' age at the time transplant of surgery, gender, indication for transplantation, date of transplantation, unilateral vs. bilateral procedure, and date and cause of death when applicable. All primary lung transplant patients were included in the analysis. Retransplantations were excluded from analysis. Lung allocation scores were obtained for patients who had these calculated as part of the pretransplantation work-up. We determined presence or absence of coronary artery disease based on documentation in the patient's medical record. Our institution's recipient selection process includes coronary catheterization in all patients over 45 years of age and in those with significant cardiac risk factors. Any documentation of $60 \%$ or greater stenosis of a coronary artery by angiography was considered as positive for CAD, as well as any documented history of invasive coronary intervention. When identifying patients with $\mathrm{CAD}$, individual patients were counted only once irrespective of number of transplants received. We classified the method of treatment of $\mathrm{CAD}$ as medical management, percutaneous coronary intervention (PCI), or coronary artery bypass grafting (CABG) based on documentation in the medical record. We did not further classify disease as single, double, or triple vessel, nor did we include specific medications used in medical management, nor echocardiographic, nuclear perfusion, or exercise stress testing in our analysis. Post-transplantation survival was estimated using the Kaplan-Meier method and statistical significance determined using the log-rank test. Analysis was performed comparing all patients without CAD to all patients with $\mathrm{CAD}$, as well as propensity matching 3:1 (No CAD:CAD) for age, gender, and indication for transplant. Differences in gender and indication for transplant between the CAD and non-CAD groups were calculated using Fisher's exact test, and differences in lung allocation score and age were calculated using a paired t test. When comparing the pre to post-LAS cohorts, we used May 1, 2005 as the date demarcating the change between the two eras. In comparing these two eras, differences in gender, CAD status, and indication for transplant were again calculated using Fisher's exact test, and differences in age were calculated using a paired t test. Binary logistic regression was used to determine impact of CAD on postoperative atrial fibrillation. A $p$ value < 0.05 (two-sided) was considered statistically significant, and analyses were performed using SAS statistical software (Cary, NC) for Windows.

\section{Results}

We identified 329 patients who underwent LTX during the study period. 26 (7.9\%) patients had documentation of CAD prior to LTX. Of these patients, 4 (15.4\%) had CAD managed with surgical revascularization, 9 (34.6\%) were managed with percutaneous coronary intervention with deployment of intracoronary stent (PCI), and 13 (50\%) were managed medically. Management patterns of CAD did not change between the two eras, but the small sample size Patients with CAD tended to be older $(59.0+/-6.0$ years vs. $51.2+/-11.8$ years, $p=0.00167$ ), but otherwise were similar in regards to gender, lung allocation score, indication for lung transplantation, and frequency of bilateral procedure. Demographic differences between the two patient groups are detailed in table 1 . The two indications for LTX that had the highest prevalence of CAD were COPD (11/112, 9.8\%) and IPF $(9 / 85,10.5 \%)$, but this difference was not statistically significant ( $p=0.88$ ). The median unadjusted post-transplant survival for patients without CAD was 9.47 years vs. 4.21 years for recipients with CAD (Log Rank $p=0.0068$ ). Kaplan-Meier survival curves for the two groups are presented in figure 1. When comparing causes of death, there was no difference in unadjusted cardiovascular mortality between patients who had a pre-transplant diagnosis of CAD (1/13 deaths, $7.7 \%)$ vs those who did not [(2/90 deaths, $2.2 \%), p=0.336]$, nor was there any significant difference in causes of death between the two groups (Table 1). Patients with a pre-transplant diagnosis of CAD, paradoxically, had a lower risk of developing postoperative atrial fibrillation (HR 0.133, CI 0.030-0.583, $p$ $=0.007)$. When comparing the two transplant eras, patients transplanted after the LAS tended to be older (53.7+/-5.8years vs. $49.6+/-12.1$ years, $p=0.0083)$. More bilateral procedures were performed in the post-LAS era [46.6\% (88/189 total 


\begin{tabular}{|c|c|c|c|}
\hline Variable & No CAD $(n=303)$ & CAD $(n=26)$ & $p$-value \\
\hline Average age (years) & $51.2+/-11.8$ & $59.0+/-6.0$ & 0.00167 \\
\hline Male Gender & $202(66.7 \%)$ & $20(76.9 \%)$ & 0.38 \\
\hline Bilateral Procedure (142/337 total procedures) & $43.4 \%(134 / 309$ total procedures) & $28.6 \%$ (8/28 total procedures) & 0.13 \\
\hline Heart-Lung Transplant & $6 / 309$ procedures & $0 / 28$ procedures & 1.00 \\
\hline Average Lung Allocation Score $(n=148)$ & $42.6+/-12.6(n=135)$ & $43.5+/-19.3(n=13)$ & 0.27 \\
\hline \multicolumn{4}{|l|}{ Primary Pulmonary Diagnosis } \\
\hline Alpha-1 Antitrypsin Deficiency & $9.6 \%(29)$ & $3.6 \%(1)$ & 0.49 \\
\hline Bronchiectasis & $1.0 \%(3)$ & 0 & 1 \\
\hline COPD/Emphysema & $33.3 \%(101)$ & $39.3 \%(11)$ & 0.39 \\
\hline Cystic Fibrosis & $15.8 \%(48)$ & 0 & 1.00 \\
\hline Dilated Myopathy:Viral & $0.3 \%(1)$ & 0 & 1.00 \\
\hline Eisenmeiger's Syndrome/CHD & $1.0 \%(3)$ & 0 & 1.00 \\
\hline Hermansky Pudlak Syndrome & $0.3 \%(1)$ & 0 & 1.00 \\
\hline Histiocytosis X & $0.3 \%(1)$ & 0 & 1.00 \\
\hline Hypersensitivity Pneumonitis & $0.7 \%(2)$ & 0 & 1.00 \\
\hline Idiopathic Pulmonary Fibrosis & $25.4 \%(77)$ & $32.1 \%(9)$ & 0.35 \\
\hline Interstitial Pneumonitis & $0.3 \%(1)$ & 0 & 1.00 \\
\hline Lung Disease: Other & $1.0 \%(3)$ & 0 & 1.00 \\
\hline Lymphangioleimyomatosis & $1.3 \%(4)$ & 0 & 1.00 \\
\hline Mixed Connective Tissue Disease & $0.3 \%(1)$ & 0 & 1.00 \\
\hline Obliterative bronchiolitis, non retransplant & $1.0 \%(3)$ & 0 & 1.00 \\
\hline Occupational Lung Disease, Other & $0.3 \%(1)$ & 0 & 1.00 \\
\hline Primary Pulmonary Hypertension & $2.3 \%(7)$ & $3.6 \%(1)$ & 0.51 \\
\hline Pulmonary Fibrosis, Secondary & $1.3 \%(4)$ & $7.1 \%(2)$ & 0.074 \\
\hline Pulmonary Vascular Disease & $0.3 \%(1)$ & 0 & 1.00 \\
\hline Rheumatoid Disease & $0.3 \%(1)$ & 0 & 1.00 \\
\hline Sarcoidosis & $2.6 \%(8)$ & $7.1 \%(2)$ & 0.183 \\
\hline Scleroderma & $0.6 \%(2)$ & 0 & 1.00 \\
\hline ANCA associated granulomatous vasculitis (Wegener's) & $0.3 \%(1)$ & 0 & 1.00 \\
\hline Cause of Death & $(n=90)$ & $(n=13)$ & \\
\hline Cardiovascular: Myocardial Infarction & $2.2 \%(2)$ & $7.7 \%(1)$ & 0.336 \\
\hline Cardiovascular: Other & $2.2 \%(2)$ & 0 & 1.00 \\
\hline Cerebrovascular & $3.3 \%(3)$ & 0 & 1.00 \\
\hline Hemorrhage & $3.3 \%(3)$ & $7.7 \%(1)$ & 0.422 \\
\hline Infection & $22.2 \%(20)$ & 0 & 0.068 \\
\hline Malignancy & $13.3 \%(12)$ & $7.7 \%(1)$ & 1.00 \\
\hline Multiple Organ System Failure & $1.1 \%(1)$ & $7.7 \%(1)$ & 0.486 \\
\hline Pulmonary Embolism & $1.1 \%(1)$ & $7.7 \%(1)$ & 0.152 \\
\hline Pulmonary: ARDS/Respiratory Failure & $23.3 \%(21)$ & $15.4 \%(4)$ & 0.512 \\
\hline Pulmonary: Bronchiolitis & $4.4 \%(4)$ & (0) & 1.00 \\
\hline Graft Failure: Primary & $10 \%(9)$ & $15.4 \%(2)$ & 0.63 \\
\hline Unknown & $10 \%(9)$ & $15.4 \%(2)$ & 0.528 \\
\hline
\end{tabular}

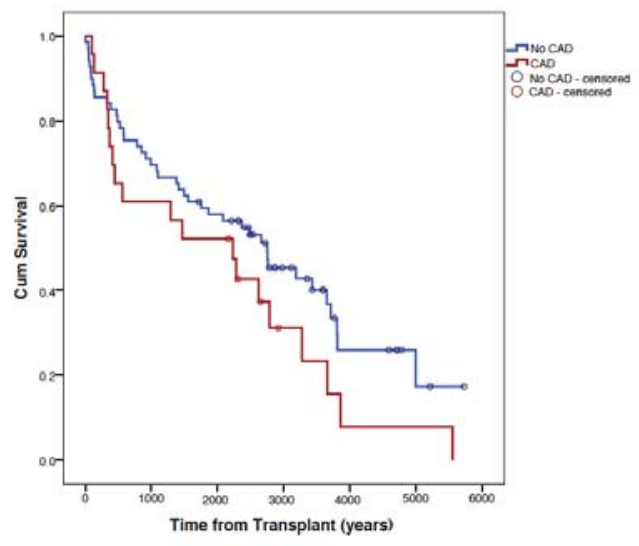

Figure 1: Propensity Matched Survival by Coronary Disease Status. CAD: Coronary Artery Disease. procedures) vs. $36.5 \%$ (54/148 total procedures)], but this difference was not statistically significant $(p=0.0753)$. Although there was a significant increase in transplantations for IPF in the post-LAS era (15/145 vs. $71 / 184$ patients, $p$ $<0.001$ ), this was not accompanied with an increase in the prevalence of CAD in patients transplanted in the post-LAS era [9.2\% (17/184 patients) vs $6.2 \%(9 / 145$ patients), $p=$ $0.411]$. Following the implementation of the LAS, there was a significant decrease in the percentage of patients transplanted for COPD [40.7\% (59/145 patients pre-LAS vs. $28.8 \%$ (53/184 patients post-LAS) $p=0.0263$ ], and for cystic fibrosis [20\% (29/145 patients pre-LAS) vs. $10.3 \%$ (19/184 patients postLAS), $p=0.0178$ ]. Differences in patient characteristics are detailed in table 2 . 
Table 2: Comparison by Transplant Era

\begin{tabular}{|c|c|c|c|}
\hline Variable & Pre-LAS era $(n=145)$ & Post-LAS era $(n=184)$ & $p$ - value \\
\hline Average age (years) & $49.6+/-12.1$ & $53.7+/-5.8$ & 0.0083 \\
\hline Male Gender & $64.1 \%(93)$ & $70.3 \%(129)$ & 0.29 \\
\hline Bilateral Procedure (142/337 total procedures) & $36.5 \%$ (54/148 total procedures) & $46.6 \%(88 / 189$ total procedures) & 0.0753 \\
\hline Heart-Lung Transplant & $3.4 \%(5 / 148$ procedures $)$ & $0.5 \%(1 / 189$ procedures $)$ & 0.0905 \\
\hline \multicolumn{4}{|l|}{ Primary Pulmonary Diagnosis } \\
\hline Alpha-1 Antitrypsin Deficiency & $12.4 \%(18)$ & $6.5 \%(12)$ & 0.0822 \\
\hline Bronchiectasis & $0.7 \%(1)$ & $1.1 \%(2)$ & 1.00 \\
\hline COPD/Emphysema & $40.7 \%(59)$ & $28.8 \%(53)$ & 0.0263 \\
\hline Cystic Fibrosis & $20 \%(29)$ & $10.3 \%(19)$ & 0.0178 \\
\hline Dilated Myopathy:Viral & $0.7 \%(1)$ & 0 & 1.00 \\
\hline Eisenmeiger's Syndrome/CHD & $1.4 \%(2)$ & $0.5 \%(1)$ & 0.58 \\
\hline Hermansky Pudlak Syndrome & 0 & $0.5 \%(1)$ & 1.00 \\
\hline Histiocytosis $\mathrm{X}$ & $0.7 \%(1)$ & 0 & 1.00 \\
\hline Hypersensitivity Pneumonitis & 0 & $1.1 \%(2)$ & 0.51 \\
\hline Idiopathic Pulmonary Fibrosis & $10.3 \%(15)$ & $38.6 \%(71)$ & $<0.001$ \\
\hline Interstitial Pneumonitis & 0 & $0.5 \%(1)$ & 1.00 \\
\hline Lung Disease: Other & $1.4 \%(2)$ & $0.5 \%(1)$ & 0.585 \\
\hline Lymphangioleimyomatosis & $2.1 \%(3)$ & $0.5 \%(1)$ & 0.324 \\
\hline Mixed Connective Tissue Disease & 0 & $0.5 \%(1)$ & 1.00 \\
\hline Obliterative bronchiolitis, non retransplant & 0 & $1.6 \%(3)$ & 0.259 \\
\hline Occupational Lung Disease & $0.7 \%(1)$ & 0 & 0.44 \\
\hline Primary Pulmonary Hypertention & $4.8 \%(7)$ & $1.1 \%(1)$ & 0.0238 \\
\hline Pulmonary Fibrosis, Secondary & $2.1 \%(3)$ & $1.6 \%(3)$ & 1.00 \\
\hline Pulmonary Vascular Disease & $0.7 \%(1)$ & 0 & 0.44 \\
\hline Rheumatoid Disease & 0 & $0.5 \%(1)$ & 1.00 \\
\hline Sarcoidosis & $1.4 \%(2)$ & $4.4 \%(8)$ & 0.195 \\
\hline Scleroderma & 0 & $1.1 \%(2)$ & 0.51 \\
\hline ANCA associated granulomatous vasculitis (Wegener's) & 0 & $0.5 \%(1)$ & 1.00 \\
\hline Cause of Death & $(n=63)$ & $(n=41)$ & \\
\hline Cardiovascular: Myocardial Infarction & $1.6 \%(1)$ & $4.9 \%(2)$ & 0.560 \\
\hline Cardiovascular: Other & $1.6 \%(1)$ & $2.4 \%(1)$ & 1.00 \\
\hline Cerebrovascular & $3.2 \%(2)$ & $2.4 \%(1)$ & 1.00 \\
\hline Hemorrhage & $6.4 \%(4)$ & 0 & 0.152 \\
\hline Infection & $22.2 \%(14)$ & $4.9 \%(2)$ & 0.024 \\
\hline Malignancy & $17.5 \%(11)$ & $4.9 \%(2)$ & 0.0723 \\
\hline Multiple Organ System Failure & $4.8 \%(3)$ & $14.6 \%(6)$ & 0.1497 \\
\hline Pulmonary Embolism & $1.6 \%(1)$ & $2.4 \%(1)$ & 1.00 \\
\hline Pulmonary: ARDS/Respiratory Failure & $15.9 \%(10)$ & $34.1 \%(14)$ & 0.0354 \\
\hline Pulmonary: Bronchiolitis & $6.3 \%(4)$ & 0 & 0.152 \\
\hline Graft Failure: Primary & $9.5 \%(6)$ & $12.2 \%(5)$ & 0.749 \\
\hline Unknown & $6.3 \%(4)$ & $12.2 \%(5)$ & 0.312 \\
\hline History of CAD $(n=26)$ & $6.2 \%(9)$ & $9.2 \%(17)$ & 0.411 \\
\hline \multicolumn{4}{|l|}{ Management of CAD } \\
\hline Surgical Revascularization & 1 & 3 & \\
\hline Percutaneous Coronary Intervention & 4 & 5 & \\
\hline Medical & 4 & 9 & \\
\hline
\end{tabular}

CAD: Coronary Artery Disease; ARDS: Acute Respiratory Distress Syndrome; CHD: Congenital Heart Disease, ANCA: Anti-Neutrophil Cytoplasmic Antibody

\section{Discussion}

In our retrospective single institution series, we observed that patients with a preoperative diagnosis of CAD had lower long-term survival rates after lung transplant compared to transplanted patients without a pre-transplant diagnosis of CAD. These findings differ from other retrospective series which report equivalent outcomes in patients with CAD who undergo revascularization prior to or concomitant with LTX as compared to patients without CAD [9,21-25]. However, in our study deaths attributable to cardiovascular causes were similar between patients with and patients without pretransplant CAD, so the inferior survival observed can not necessarily be attributed to CAD alone. We did observe that our patients with CAD were more likely to be older, and age is an independent risk factor for decreased survival following LTX [26]. Although not statistically different, there was a trend towards greater bilateral procedure performed in non-CAD patients compared to those with CAD. Large registries have reported an overall survival benefit of bilateral transplantation (BLT) compared to single lung transplantation (SLT) [20], and it is possible that patients with preoperative CAD were more 
likely to be offered SLT. This may be due to a perception of poorer performance status or that more frequent BLT in the CAD cohort would have resulted in more perioperative deaths. However, the superiority of BLT has not been consistently demonstrated, with some series reporting equivalent outcomes after SLT [27]. Unlike previous population-level studies [10-12] that demonstrated an association between IPF and CAD, in our series patients with IPF did not have a higher prevalence of CAD compared to patients with other diagnoses warranting lung transplantation. It is unlikely that there were patients in the non-CAD arm that had undiagnosed significant $\mathrm{CAD}$ given the intensive recipient selection process in which coronary catheterization is frequently performed. It is likely that the majority of patients with both end-stage IPF and CAD (and certainly those with severe CAD) were deemed not to be candidates for LTX and were ultimately not listed, causing a selection bias among the transplanted population. Since we did not include patients who were referred for LT but not listed, we cannot comment on factors governing listing for patients with preoperative CAD in this study.

Our study has several weaknesses. The retrospective nature of the study being the most relevant. Though data points in the SRTR consistent and prospectively gathered, this retrospective, review was not designed to detect differences between causes of death. Since cardiovascular causes of death are relatively infrequent in the lung transplant population, especially compared to other causes such as infection or graft failure, the number of patients required to detect a difference in cardiovascular causes would be much greater than our cohort. Furthermore, coronary artery disease is not a binary but a continuous, dynamic variable. By defining CAD status merely as the presence or absence of the diagnosis, we cannot comment on how burden of disease influenced survival, nor can we comment on the appropriateness of the management of CAD which may also have influenced survival. 13 of the 26 patients with CAD had their disease managed medically, indicating the severity of CAD in this cohort was relatively low.

In conclusion, we observed that patients with a preoperative diagnosis of coronary artery disease have a lower long-term survival after lung transplantation compared to transplanted patients who did not have a diagnosis of CAD, but we cannot attribute the differences in survival to cardiovascular causes of death. Patients with CAD prior to transplant, however, were less likely to experience new postoperative atrial fibrillation. Our study highlights the need for a systematic approach to incorporating coronary artery disease into the comprehensive recipient selection process, especially as management algorithms for CAD evolve, potentially allowing a greater number of patients with CAD to be listed for LTX.

\section{Acknowledgement}

The authors disclose no funding sources or relevant conflicts of interest for this retrospective review.

\section{References}

1. Rana A, Gruessner A, Agopian VG, Khalpey Z, Riaz IB, et al. Srvival benefit of solid-organ transplant in the united states. JAMA Surg. 2015; 150: 252-259. PubMed: https://www.ncbi.nlm.nih.gov/pubmed/25629390

2. Punch JD, Hayes DH, LaPorte FB, McBride V, Seely MS. Organ donation and utilization in the United States, 1996-2005. Am J Transplant. 2007; 7: 1327-1338.

PubMed: https://www.ncbi.nlm.nih.gov/pubmed/17428283

3. Mascia L, Pasero D, Slutsky AS, Arguis MJ, Berardino M, et al. Effect of a lung protective strategy for organ donors on eligibility and availability of lungs for transplantation: a randomized controlled trial. JAMA. 2010; 304: 2620-2627.

PubMed: https://www.ncbi.nlm.nih.gov/pubmed/21156950

4. Leibowitz DW, Caputo AL, Shapiro GC, Schulman LL, McGregor CC, et al. Coronary angiography in smokers undergoing evaluation for lung transplantation: is routine use justified? J Heart Lung Transplant. 1994; 13: 701-703

PubMed: https://www.ncbi.nlm.nih.gov/pubmed/7947888

5. Manoushagian S, Meshkov A. Evaluation of solid organ transplant candidates for coronary artery disease. Am J Transplant. 2014; 14 2228-2234.

PubMed: https://www.ncbi.nlm.nih.gov/pubmed/25220486

6. Jones RM, Enfield KB, Mehrad B, Keeley EC. Prevalence of obstructive coronary artery disease in patients undergoing lung transplantation: case series and review of the literature. Catheter Cardiovasc Interv. 2014; 84: 1-6.

PubMed: https://www.ncbi.nlm.nih.gov/pubmed/24136925

7. Choong CK, Meyers BF, Guthrie TJ, Trulock EP, Patterson GA, et al Does the presence of preoperative mild or moderate coronary artery disease affect the outcomes of lung transplantation? Ann Thorac Surg. 2006; 82: 1038-1042.

PubMed: https://www.ncbi.nlm.nih.gov/pubmed/16928531

8. Lee R, Meyers BF, Sundt TM, Trulock EP, Patterson GA. Concomitant coronary artery revascularization to allow successful lung transplantation in selected patients with coronary artery disease. J Thorac Cardiovasc Surg. 2002; 124: 1250-1251.

PubMed: https://www.ncbi.nlm.nih.gov/pubmed/12447202

9. Sherman W, Rabkin DG, Ross D, Saggar R, Lynch JP 3rd, et al. Lung transplantation and coronary artery disease. Ann Thorac Surg. 2011; 92: 303-308.

PubMed: https://www.ncbi.nlm.nih.gov/pubmed/21718862

10. Dalleywater W, Powell HA, Hubbard RB, Navaratnam V. Risk factors for cardiovascular disease in people with idiopathic pulmonary fibrosis: a population-based study. Chest. 2015; 147: 150-156.

PubMed: https://www.ncbi.nlm.nih.gov/pubmed/25121965

11. Izbicki G, Ben-Dor I, Shitrit D, Bendayan D, Aldrich TK, et al. The prevalence of coronary artery disease in end-stage pulmonary disease: is pulmonary fibrosis a risk factor? Respir Med. 2009; 103: 1346-1349. PubMed: https://www.ncbi.nlm.nih.gov/pubmed/19362458

12. Nathan SD, Basavaraj A, Reichner C, Shlobin OA, Ahmad S, et al. Prevalence and impact of coronary artery disease in idiopathic pulmonary fibrosis. Respir Med. 2010; 104: 1035-1041.

PubMed: https://www.ncbi.nlm.nih.gov/pubmed/20199856

13. Burlingham WJ, Love RB, Jankowska-Gan E, Haynes LD, Xu Q, et al. IL-17-dependent cellular immunity to collagen type $\mathrm{V}$ predisposes to obliterative bronchiolitis in human lung transplants. J Clin Invest. 2007; 117: 3498-3506.

PubMed: https://www.ncbi.nlm.nih.gov/pubmed/17965778

14. Park AC, Huang G, Jankowska-Gan E, Massoudi D, Kernien JF, et al. 
Mucosal administration of collagen $\mathrm{V}$ ameliorates atherosclerotic plaque burden by inducing IL-35-dependent tolerance. J Biol Chem. 2015. PubMed: https://www.ncbi.nlm.nih.gov/pubmed/26721885

15. Francois A, Gombault A, Villeret B, Alsaleh G, Fanny M, et al. B cell activating factor is central to bleomycin- and IL-17-mediated experimental pulmonary fibrosis. J Autoimmun. 2015; 56: 1-11.

PubMed: https://www.ncbi.nlm.nih.gov/pubmed/25441030

16. Wilkes DS, Chew T, Flaherty KR, Frye S, Gibson KF, Kaminski N, et al. Oral immunotherapy with type $\mathrm{V}$ collagen in idiopathic pulmonary fibrosis. Eur Respir J. 2015; 45: 1393-1402.

PubMed: https://www.ncbi.nlm.nih.gov/pubmed/25614165

17. Kistler KD, Nalysnyk L, Rotella $P$, Esser D. Lung transplantation in idiopathic pulmonary fibrosis: a systematic review of the literature. BMC Pulm Med. 2014; 14: 139.

PubMed: https://www.ncbi.nlm.nih.gov/pubmed/25127540

18. Osaki S, Maloney JD, Meyer KC, Cornwell RD, Edwards NM, et al. The impact of the lung allocation scoring system at the single national Veterans Affairs Hospital lung transplantation program. Eur J Cardiothorac Surg. 2009; 36: 497-501.

PubMed: https://www.ncbi.nlm.nih.gov/pubmed/19394854

19. Merlo CA, Weiss ES, Orens JB, Borja MC, Diener-West M, et al. Impact of U.S. Lung Allocation Score on survival after lung transplantation. J Heart Lung Transplant. 2009; 28: 769-775.

PubMed: https://www.ncbi.nlm.nih.gov/pubmed/19632571

20. Yusen RD, Edwards LB, Kucheryavaya AY, Benden C, Dipchand Al, et al. The registry of the International Society for Heart and Lung Transplantation: thirty-first adult lung and heart-lung transplant report-2014; focus theme: retransplantation. J Heart Lung Transplant. 2014; 33: 1009-1024.

PubMed: https://www.ncbi.nlm.nih.gov/pubmed/25242124
21. Seoane L, Arcement LM, Valentine VG, McFadden PM. Long-term survival in lung transplant recipients after successful preoperative coronary revascularization. J Thorac Cardiovasc Surg. 2005; 130: 538-541. PubMed: https://www.ncbi.nlm.nih.gov/pubmed/16077424

22. Patel VS, Palmer SM, Messier RH, Davis RD. Clinical outcome after coronary artery revascularization and lung transplantation. Ann Thorac Surg. 2003; 75: 372-377.

PubMed: https://www.ncbi.nlm.nih.gov/pubmed/12607642

23. Patel VS, Messier RH, Palmer SM, Davis RD. Coronary artery revascularization in eligible lung transplant recipients. J Heart Lung Transplant. 2001; 20: 223.

PubMed: https://www.ncbi.nlm.nih.gov/pubmed/11250417

24. Zanotti G, Hartwig MG, Castleberry AW, Martin JT, Shaw LK, et al. Preoperative mild-to-moderate coronary artery disease does not affect long-term outcomes of lung transplantation. Transplantation. 2014; 97: 1079-1085.

PubMed: https://www.ncbi.nlm.nih.gov/pubmed/24646771

25. Castleberry AW, Martin JT, Osho AA, Hartwig MG, Hashmi ZA, et al. Coronary revascularization in lung transplant recipients with concomitant coronary artery disease. Am J Transplant. 2013; 13: 2978-2988. PubMed: https://www.ncbi.nlm.nih.gov/pubmed/24102830

26. Hertz MI, Aurora P, Benden C, Christie JD, Dobbels F, et al. Scientific Registry of the International Society for Heart and Lung Transplantation: introduction to the 2011 annual reports. J Heart Lung Transplant. 2011; 30: 1071-1077.

PubMed: https://www.ncbi.nlm.nih.gov/pubmed/21962015

27. Julliard WA, Meyer KC, De Oliveira NC, Osaki S, Cornwell RC, et al. The presence or severity of pulmonary hypertension does not affect outcomes for single-lung transplantation. Thorax. 2015. PubMed: https://www.ncbi.nlm.nih.gov/pubmed/26621135 